\title{
Doctor Gustavo Aldereguía Lima: luchador e higienista social
}

\section{Doctor Gustavo Aldereguía Lima: social fighter and hygienist}

\author{
Dr. Gregorio Delgado García \\ Ministerio de Salud Pública. La Habana, Cuba.
}

\section{INTRODUCCIÓN}

No es nada fácil, lo hemos manifestado en otros momentos también abordar críticamente el rico quehacer de una vida tan útil como la del doctor Gustavo Aldereguía Lima en su doble aspecto de incansable luchador social y eminente científico. Para muchos ha sido esta dualidad al parecer imposible de lograr y hasta antagónica, una prueba de que no le está vedado a quien dedica su vida a dar solución a los problemas políticos y sociales de su país, sobre todo en el mundo subdesarrollado, el lograr un lugar prominente ya sea en el ámbito de las letras o en el de las ciencias.

En nuestra historia abundan los ejemplos en el campo de las letras donde son paradigmas nuestro héroe nacional José Martí, genio a la vez político y literario y nuestro Juan Marinello Vidaurreta, figura mayor de la ensayística latinoamericana y a la vez dirigente revolucionario de proyección internacional.

Pero en el campo de las ciencias donde sin duda se necesita mayor dedicación para lograr una obra de valor, los ejemplos no son tan numerosos y yo me atrevería a afirmar que solo es comparable al doctor Gustavo Aldereguía en esa doble vertiente, el doctor Eusebio Hernández Pérez, que en las luchas por la independencia de nuestra patria contra España, alcanzó el grado de General de Brigada, que durante la etapa de la república liberal burguesa mantuvo una conducta intransigente

http://scielo.sld.cu 
frente a la injerencia imperialista norteamericana en nuestros destinos nacionales y que en el I Congreso Nacional Estudiantil de 1923, ya muy viejo y enfermo, se situó como profesor al lado de los estudiantes más radicales dirigidos por Julio Antonio Mella e hizo pública profesión de fe marxista en un valiente discurso ante la Asamblea Universitaria, y que no abjuró de ella en el resto de su vida y que junto a esta larga trayectoria revolucionaria desarrolló una notable labor científica que ha permitido catalogarlo como el iniciador en nuestro país de la moderna obstetricia y de la puericultura y creador indiscutible de la Escuela de Obstetras Cubanos.

Es interesante decir que Aldereguía, que fue discípulo de Eusebio Hernández en la Cátedra de Obstetricia con su Clínica durante el curso 1916-1917, mantuvo desde esa época y hasta la muerte del viejo revolucionario una inquebrantable amistad que se estrechó más en la Asociación de Amigos de Rusia, que fundó Aldereguía en 1920 con Eusebio Adolfo Hernández, hijo del general mambí y durante el I Congreso Nacional Estudiantil de 1923.

\section{LUCHADOR E HIGIENISTA SOCIAL}

En la personalidad y en el quehacer futuro de la vida del doctor Aldereguía van a influir, reconocido por él mismo, tres hechos dolorosos, dos de ellos en los mismos comienzos de su existencia, que aunque indiscutiblemente no lo constituyen todo, sí van a ser determinantes en la formación de su carácter y de su voluntad de lucha frente a la tuberculosis y a la injusticia social.

Estos hechos lo fueron, la muerte por tuberculosis de su madre cuando solo contaba seis meses de edad y sin apenas haber recibido algunos besos de ella, como le escribiría su padre al dorso de un retrato que el hijo guardó amorosamente toda su vida; la muerte de su progenitor en accidente de ferrocarril ocurrido en su presencia cuando contaba solamente diez años y la muerte de su primer hijo de meningitis tuberculosa a edad muy temprana.

Su orfandad, sin embargo, fue mitigada en gran medida por el cariño que siempre le demostró su tío paterno Alfredo Aldereguía, quien fue para él un verdadero padre y le costeó todos sus estudios hasta graduarse de médico.

En su etapa de estudiante va a comenzar a forjarse, unida a su formación cultural y científica, su faena revolucionaria. En el Instituto de Segunda Enseñanza de Matanzas es elegido presidente de la Asociación de Estudiantes y en la Facultad de Medicina de la Universidad de La Habana, funda en 1917, con tres compañeros, la Revista de la Asociación de Estudiantes de Medicina, donde van a aparecer sus primeros artículos.

Una vez graduado de médico inicia su ejercicio profesional en el central azucarero "Santa Gertrudis", situado en los alrededores de Banagüises, pequeño caserío de la provincia de Matanzas, donde va a permanecer durante cuatro años y es esto indiscutiblemente otro factor determinante para el futuro de su vida.

Es allí donde van a cuajar los moldes definitivos de su pensamiento político y social y donde va a decidir su próxima especialización.

En este mismo ambiente de caciquismo de hacendados y politiqueros, donde con tanta frecuencia el médico hundía su dignidad en el servicio a los explotadores para entrar a formar parte finalmente de ellos, Gustavo Aldereguía no se deja ahogar

http://scielo.sld.cu 
por el medio sino que muy lejos de esto se adentra en el estudio profundo de los males sociales de su país y de su tiempo bebiendo esos conocimientos en la fuente abundante que constituía la Revista de Filosofía Argentina, fundada por José Ingenieros, una de las mas valiosas publicaciones que sobre esta materia se han impreso en lengua hispana, lo que le permite muy pronto poder adentrarse en el conocimiento de los clásicos del marxismo y también por el contacto íntimo no con los poderosos y explotadores de la zona, sino con los infelices y explotados, que le dan, como a él le gustaba decir, su experiencia ganada en el trabajo y en la lucha por la vida y su temperatura de hombre.

Es en este medio rural y por propia iniciativa, que se aleja del ejercicio exclusivo de la medicina asistencial privada para emprender una aleccionadora labor de higienista social, que aún hoy puede servir de programa para nuestros jóvenes facultativos en su ejercicio médico social rural.

En "Santa Gertrudis" en marzo de 1921 escribe el primer artículo que le conocemos, "La crisis de un sistema político", en el que se puede apreciar, nítidamente ya, el marco de su pensamiento político definitivo, allí se lee:

Francia... es el republicanismo decadente, la antorcha que vacila... es la negación actual de los principios que sentó como mejores. Rusia es el mañana, la eterna esperanza, la afirmación más rotunda de la humanidad hacia mejores destinos, es la 'obra gigantesca cumplida por gigantes', es la ruta a seguir en medio de la noche, puestos los ojos en la fraternidad humana... Europa rehuye la república histórica y la degrada, América la pervierte y la desvía; los constructores, en tanto, se aprestan a levantarla pujante y remozada, liberándola del capitalismo, dándole por base el universo con la socialización de los medios de producción y de cambio.

Y como nunca dejó de unir la palabra a los hechos, un año antes había fundado en 1920, como ya dejamos dicho en unión de Eusebio Adolfo Hernández, la Asociación de Amigos de Rusia y logra colectar y mandar dinero en ayuda a la naciente Revolución de Octubre.

También en "Santa Gertrudis" el 15 de abril de 1922, escribe un artículo en contestación a la conferencia de divulgación pronunciada en la Academia de Ciencias Médicas, Físicas y Naturales de La Habana por el sacerdote jesuita P. Franganillo Balboa, quien tiene publicado estudios valiosos sobre artropodología y que sobre ellos basa su prestigio científico, pero que en dicha conferencia que titula "Las maravillas del cuerpo humano a la luz de la biología", que se publica en el Diario de la Marina el 31 de marzo de ese año y después en los Anales de la Academia de Ciencias, Físicas y Naturales de La Habana, se trataban de explicar los fenómenos biológicos por medio de las concepciones metafísicas mantenidas por la Iglesia Católica.

En este artículo, el segundo cronológicamente hablando que conocemos de Aldereguía, que titula: "Comentarios a una conferencia. El anti-Franganillo", refuta una por una todas las ideas en que el sacerdote biólogo apoya su tesis y demuestra un conocimiento tan acabado del desarrollo histórico del pensamiento científico, materia de la que no le enseñaron nada en ninguna de las cátedras de la Facultad de Medicina habanera, que nos lleva a pensar que estos estudios los realiza por propia orientación en su casa de Banagüises.

En esta etapa de su vida, a la cual se debe reconocer la importancia que tiene en su formación política y científica, Gustavo Aldereguía va a aumentar sus conocimientos médicos teóricos con el estudio asiduo y detenido de obras actualizadas; a sedimentar los conocimientos que trajo de la Universidad y relacionarlos con los factores que los engendran y extienden, para llegar a lograr un conocimiento temprano y bien 
sistematizado de la higiene social que comenzaría a exponer un año después de su partida de Banagüises en sus clases de Medicina Social de la Universidad Popular "José Martí", de la que es uno de los fundadores con Julio A. Mella, y en la que permanece como tal profesor durante toda su corta existencia de 1923 a 1927.

Este conocimiento de la higiene social, del que es indiscutiblemente un precursor en Cuba en su concepción materialista dialéctica, lo va a acrecentar con el estudio y el ejercicio de la medicina interna en general y de la tuberculosis en particular al lado de dos grandes maestros de la clínica como fueron los profesores Luis Ortega Bolaños y Pedro Castillo Martínez, con los que trabajó dos años de 1923 a 1925 en las cátedras de Clínica Médica, a una de las cuales arriba por oposición como ayudante graduado en 1923, a un año escaso de haber salido de su ejercicio médico rural.

En 1925, y esto da la medida de los progresos de sus conocimientos sobre tuberculosis, obtiene, por oposición también, una plaza de tisiólogo de la Quinta de Salud "Nuestra Señora de la Covadonga", plaza extraordinariamente ambicionada en esos tiempos, donde va a ganarse el respeto y la consideración de todos los médicos de la institución por su habilidad y conocimientos en el manejo del neumotórax artificial, aun de quien estaba tan lejos de sus convicciones médico sociales y políticas como el archirreaccionario doctor Octavio Montoro Saladrigas, quien es indiscutiblemente un internista notable y hombre de cultura vasta y profunda.

Pero a pesar de esta dedicación al estudio, su labor política es de una actividad asombrosa por estos años. El día 4 de diciembre de 1922 pronuncia en el Aula Magna de la Universidad de La Habana un vibrante discurso en pro de la reforma universitaria con el que presenta al profesor argentino doctor José Arce, entonces Rector de la Universidad de Buenos Aires, quien lee su famosa conferencia sobre la reforma universitaria en la Argentina, acto que constituye la chispa que hizo detonar la revolución estudiantil de 1923.

Participa en la organización y desarrollo del I Congreso Nacional Estudiantil, al que asiste, a pesar de ser graduado, como delegado de la Asociación de Estudiantes de Manzanillo y por la revista universitaria Juventud fundada y dirigida por Julio Antonio Mella y allí se va a enfrentar con encendidos discursos a la peor reacción de derecha representada por la desde entonces figura retrógrada de Emilio Núñez Portuondo, que no solo es graduado de abogado y diplomático sino candidato a Representante a la Cámara por el Partido Liberal.

También en esta época asiste a las reuniones del famoso Grupo Minorista integrado por intelectuales y artistas de ideas progresistas y de izquierda, entre ellos, Emilio Roig de Leuchsenring, Juan Marinello, Rubén Martínez Villena, José Z. Tallet, Juan Antiga, Elías Entralgo y otros, y además se relaciona con prohombres de nuestra cultura como Enrique José Varona y Fernando Ortiz.

En 1925 está presente en la fundación de la Federación Médica de Cuba junto al insigne médico, profesor Juan Guiteras Gener y siempre seguirá unido a ella y después al Colegio Médico Nacional como uno de sus activos y combativos dirigentes.

Por su preparación científica y su amor probado a la Universidad de La Habana, no es extraño que deseara llegar hasta una de sus cátedras para llevar con él los aires renovadores, no solo de sus conocimientos médicos sólidos y actualizados, sino de sus ideas políticas tan ajenas a aquel profesorado que se caracterizaba por su pensamiento reaccionario y del que ya se habían hecho saltar algunas figuras deshonestas en la depuración universitaria de 1923, a instancias del estudiantado con Julio Antonio Mella a la cabeza. 
No obstante estos antecedentes, Gustavo Aldereguía concurre en 1928 a las oposiciones para la cátedra auxiliar de Patología, Clínica e Higiene Terapéutica de las Enfermedades Tuberculosas, cátedra No. 22 de la Escuela de Medicina.

Llevaba a ella todo lo que debe reunir un profesor de enseñanza superior: conocimientos bien cimentados y actualizados de la materia que va a explicar, cultura general amplia y profunda penetrada de las ideas y de las concepciones de su época, memoria feliz que le facilita utilizar con soltura sus conocimientos, elocuencia que le permite exponer con claridad y facilidad sus ideas y una conducta moral pública y privada que ayuda con el ejemplo a formar ciudadanos en el más alto sentido de esta palabra.

Todo lo reunía Aldereguía, pero era temido por una gran parte de aquel claustro que conocía sus hechos y su ideología. El mismo nos ha dejado en páginas luminosas como surgió la zancadilla que le arrebató la cátedra y cómo fue su reacción limpia y valiente, pues ese relato es verdaderamente antológico para la historia de los ejercicios de oposición a cátedras en la Universidad de aquella época.

Aquel aparente revés que hoy podemos catalogar como un triunfo revolucionario pues dio paso a la única protesta viril y frontal que se realizó en la Universidad de La Habana contra estos inmorales procedimientos, no amilana su espíritu científico y así publica en 1930, su libro "Estudios sobre tuberculosis" que contiene ocho de sus más importantes trabajos médicos, sobre esta enfermedad y que dedica con palabras conmovedoras:

Al recuerdo de todos los míos que fallecieron tuberculosos. A todos los enfermos que pasaron por mi servicio del Sanatorio "Covadonga"; por cuyo recobramiento luché cuanto pude; a la memoria de los que sucumbieron, a los que viven en salud actual, a los que sufren y confían esperanzados.

No conforme nunca con sus conocimientos viaja entonces a los Estados Unidos y en la Trudeau School of Tuberculosis se gradúa de especialista en 1931. Ya está convertido en un prestigioso científico y publicista médico que presenta el resultado de sus estudios en congresos nacionales e internacionales, a cuyo consultorio concurre desde el rico burgués que busca en él la calidad de su ciencia, sin importarle sus ideas, hasta el más pobre obrero, a quien nada cobra por sus servicios, entre ellos a cuanto líder proletario se enferme de tuberculosis, como el humilde Joaquín Valdés, obrero tabacalero y uno de los fundadores del Partido Comunista de Cuba.

Pero la tragedia del pueblo cubano, en aquel momento bajo las garras ensangrentadas del dictador Gerardo Machado Morales, no espera de sus mejores hijos solamente el cultivo brillante de las ciencias o letras, por muy útil que esto sea, demanda actitudes firmes y enérgicas y los mayores sacrificios.

Gustavo Aldereguía, que labora junto a Mella en sus actividades revolucionarias, que es su médico en la famosa huelga de hambre y que logra salvarlo momentáneamente para la Revolución y sacarlo clandestinamente de Cuba, rompe lanzas definitivamente contra la dictadura. Cierra su consulta particular nada menos que durante siete años a partir de 1931. Empuña las armas y desembarca en Gibara junto a los legionarios de Emilio Laurent, es herido y al fracasar la invasión es detenido y encarcelado durante seis meses. Pierde su plaza de especialista en la Quinta "Covadonga" en agosto de 1932 al secundar la huelga médica contra los centros regionales y sufre su primer exilio político. 
A la caída de Machado, Aldereguía, que se había iniciado en las luchas federativas médicas en la Asamblea de Sancti Spíritus, en la que en unión de otros facultativos de ideas progresistas y opositores al régimen constituye el grupo de los "jibaritos", continúa en su cargo desde el que ayuda a barrer a todos los comprometidos con la dictadura.

En aquellos momentos existe un grave problema para la Federación pues la gran mayoría de sus afiliados padecen una situación difícil, pues sumada a la grave crisis económica que se cierne sobre el país, está el problema específico de los desplazamientos por la huelga de los centros regionales y de la administración pública, todo lo cual provoca un afán muy justificado de procurarse trabajo, lo que da nacimiento a un número extraordinario de cooperativas médicas y a una competencia desleal entre ellas, en menoscabo de la atención a los enfermos.

Gustavo Aldereguía, que se había negado a regresar a su antigua plaza de la "Covadonga" en desacuerdo con la solución dada al conflicto por las directivas de las Quintas Regionales, pero que no es un desempleado pues labora en el Instituto Clínico de La Habana, propone a la Federación, como una solución que atenuara el peligro que corren los enfermos, a la vez que daba salida a la situación laboral de los médicos, la creación de una "Mutualidad Nacional de Asistencia Médica", de la que formarían parte la totalidad de los facultativos federados para darle servicio a todos los socios mutualizables, que pudieran corresponder a una gran parte del pueblo cubano por lo módico del precio de su cuota. Este proyecto fue uno de los primeros intentos por socializar la medicina en Cuba.

Es entonces cuando es nombrado el 16 de agosto de 1933, director del Sanatorio Antituberculoso "La Esperanza". Allí es donde va a tener posibilidad de aplicar, aunque sea en una escala limitada, sus ideas de higienista social. A él no se le oculta la tremenda verdad que encierra la frase del famoso profesor y tratadista inglés de la medicina interna William Osler de que "la tuberculosis es un problema social con un solo aspecto médico", pero él sabe también por experiencia ganada en las luchas estudiantiles junto a Mella la razón que este tiene al decir que los males de la universidad eran el reflejo de la sociedad a la que pertenecía y que era inútil por lo tanto tratar de mejorar aquella sin cambiar esta y que esa solución era la misma para la tuberculosis y no en balde, para cambiarla, había empuñado hasta las armas y estaba en cada momento exponiendo su vida.

Pero no podía perder aquella oportunidad y la supo aprovechar en la medida que se lo permiten las mínimas posibilidades con las que pudo contar durante todo el tiempo de su gestión. Lo que él encontró en el sanatorio lo deja plasmado en un artículo que escribe, para que nada se perdiera para la historia, con el título de "El Infierno y La Esperanza" y que publica en la revista Bohemia el 24 de diciembre de 1933.

Con escasos recursos todo lo mejora en poco tiempo. Se realizan obras de reparación en la totalidad de los pabellones y casetas, se instalan servicios para neumotórax artificial, cardiología, metabolismo basal y bacteriología. Los ingresados llegan hasta la cifra de 420 a principios de 1935.

Allí también va a convertir en realidad el sueño que la Universidad le había negado llevar a cabo, enseñar tisiología a los médicos cubanos. El verdadero virtuoso de la semiología y la patología del aparato respiratorio tiene entonces la oportunidad de crear discípulos aunque fuera por muy corto tiempo. 
El doctor José López Sánchez ha dejado escrita esta habilidad para la Clínica, que no queremos dejar de transcribir:

Gustavo perteneció a aquella falange de médicos que hacían verdaderos prodigios de diagnósticos con las manos y los oídos. Los que tuvieron alguna vez la dicha de verlo auscultar a un enfermo no podrán olvidar su paciencia, su fineza de modales, su atención escudriñadora, su bondad exquisita; si lo notaba cansado interrumpía el examen y ese lapso de tiempo lo utilizaba para darle ánimo, para impregnarle de fe en sí mismo. Ni un gesto ni una palabra molesta o desusada. Nada de brusquedades ni indiscreciones. Parece paradójico que el Gustavo orador y polemista, con ceño adusto, voz bronca y gestos violentos, como cabe a un tribuno agitador, cuando actuaba como médico fuese un hombre tan sereno, ensimismado en su quehacer. Quien era capaz de provocar una conmoción en la calle, cuando tenía el estetóscopo en sus oídos o miraba en la pantalla fluoroscópica no se inmutaba ante ningún estampido ni prestaba la menor atención a ningún vocerío, lo único valedero era el enfermo.

Su presencia destacada en la huelga de marzo de 1935 le costó su cargo de director del Sanatorio, casi perder la vida y un nuevo destierro. De su estancia en "La Esperanza" dejaría dicho:

Trabajé todo el tiempo como si fuera a ser director toda la vida y viví siempre como si tuviera que irme todas las mañanas, con las manos limpias y la frente alta, satisfecho de haber cumplido mí deber.

A pesar de que no regresa jamás a él, su ejemplo perdura siempre y muchos años después, uno de aquellos médicos que iniciaron su formación a su lado diría:

"Gustavo continuó siendo una sombra benéfica para el Sanatorio."

Y continuó el camino de la lucha social aquel eterno condotiero, como le gustaba llamarse a sí mismo el Che Guevara. Combate a la mediación intervencionista de Summer Welles, primero y a la de Cafferi, después, así como a su engendro Fulgencio Batista desde el momento mismo de su aparición en la vida pública hasta su estrepitosa huida en la madrugada del 1ro. de Enero de 1959. Igualmente combate los gobiernos corrompidos de Grau San Martín y Pío Socarrás sin debilidades ni claudicaciones de ningún tipo.

Su pluma de panfletario insobornable ni halagable le gana fama de polemista temido y muchos de sus artículos, no publicados por la prensa timorata de la época, son dados a la estampa en folletos pagados de su propio peculio.

La tragedia social del enfermo tuberculoso en nuestro medio y la explotación de que fueron víctimas por entidades privadas y estatales, así como por farsantes y malversadores de toda laya, son denunciadas y desenmascarados valientemente sus autores por su pluma, al extremo de que es proverbial que los desmanes fraguados por el tristemente célebre Consejo Superior de Tuberculosis no son mayores porque encuentran siempre en la crítica de Gustavo Aldereguía un firme muro de contención.

El consultorio de Aldereguía es siempre lugar de curación para todo revolucionario y los cuidados que le prodiga a su entrañable compañero de luchas Rubén Martínez Villena durante su clandestinidad, perseguido por los sicarios de Machado, hasta su muerte ocurrida en sus brazos, en el Sanatorio "La Esperanza" el 24 de enero de 1934, son un ejemplo de dedicación y desinterés. 
En esta institución ingresa a Martínez Villena en el pabellón "Dr. Guiteras", frente a la casa que ocupa como director para poder atenderlo en todo momento del día o de la noche.

Su hogar es también refugio abierto para todo revolucionario, no importa el trance peligroso en que se encontrara, en su consultorio vivieron, sin medir tiempo, exiliados latinoamericanos como Carlos Aponte, Esteban Pavletich, Luis Bustamante y Manuel Monteros Valdivieso.

Por eso no es de extrañar que Fidel en la Sierra Maestra hubiera querido contar con un hombre como él, a pesar de haber rebasado Aldereguía los sesenta años de edad cuando le hizo llegar su invitación con Carlos Rafael Rodríguez en 1958 y solo pudo impedir que se incorporara a los rebeldes el estar convaleciente de una intervención quirúrgica.

\section{LA CULMINACIÓN DE SU OBRA}

Con el triunfo de la Revolución Cubana culmina la obra de este gran luchador e higienista social. Ahora pondría en practica todas las ideas que ha ido madurando con el tiempo y que le hicieron expresar, en uno de sus más logrados trabajos de esta última etapa de su vida, "Epidemiología y Tuberculosis", con palabras compartidas con Etienne Burnet:

Que a la enfermedad social -y lo es la tuberculosis- le corresponde la higiene social que es: 1o. una higiene de masas, cuya aplicación no puede ser asegurada por el individuo ni por la familia; 2o. una higiene que teniendo en cuenta la desigualdad económica de las clases, en una palabra, el hecho de que hay ricos y pobres, compense las desigualdades desde el punto de vista de la higiene. Se ha podido afirmar que la Higiene Social consiste en la igualización de las clases en relación a la salud.

Este trabajo lo leyó en la Primera Reunión Nacional de Directores de Hospitales, Dispensarios Antituberculosos y Jefes de Servicios de Tisiología celebrada en La Habana en noviembre de 1961 y que más tarde recoge en su libro, en colaboración, "Estudios sobre tuberculosis pulmonar", publicado en 1963.

La instauración del socialismo en Cuba y la desaparición progresiva de las diferencias de clases permiten la aplicación sin límites de estos principios de los que él es uno de los principales impulsores desde sus cargos de Jefe del Departamento de Tuberculosis, primero en la Subsecretaría de Asistencia Médica y después en el Viceministerio de Higiene y Epidemiología y en el Grupo Nacional de Neumotisiología.

Antes de bajar a la tumba el 7 de septiembre de 1970 pudo sentir la profunda satisfacción de ver el socialismo establecido en su patria y la tuberculosis batida en retirada. Ya las madres del futuro no morirían de tuberculosis y podrían besar por muchos años a sus hijos y los niños no morirían en Cuba de meningitis tuberculosa. La obra de su vida estaba cabalmente cumplida. 


\section{BIBLIOGRAFÍA CONSULTADA}

Aldereguía Lima G. Relato histórico y Curriculum Vitae. La Habana, 1960. Folleto mecanografiado. Pp. 10-11.

Aldereguía Lima G. La crisis de un sistema político. Reproducido en: El Mundo del Domingo. Noviembre 25 de 1962. P. 8.

Aldereguía Lima G. Comentarios a una conferencia. El anti-Franganillo. Rev España Nueva. La Habana, abril 15 de 1922. Pp. 21-25.

Aldereguía Lima G. Carta al presidente de la Academia de Ciencias Médicas, Físicas y Naturales de La Habana. Archivo de la Oficina del Historiador del MINSAP. La Habana.

Aldereguía Lima G. La explotación de los tuberculosos. Ed. Cenit. La Habana, 1949. Pp. 27-30.

Aldereguía Lima G. Estudios sobre tuberculosis. Primera página sin numerar. La Habana, 1930.

Aldereguía Lima G. Epidemiología y tuberculosis. En: Estudios sobre tuberculosis pulmonar. La Habana, 1963. P. 70.

López Sánchez J. Gustavo Aldereguía G. Singular luchador contra las enfermedades humanas y sociales. Oración Finlay 1971. Pronunciada el 20 de enero de 1972 en el Paraninfo del Museo Histórico de las Ciencias "Carlos J. Finlay". Copia mecanografiada. Archivos de la Oficina del Historiador del MINSAP. La Habana. P. 18.

Recibido: 1ro. de noviembre de 2011.

Aprobado: 15 de noviembre de 2011.

Gregorio Delgado García. Historiador Médico del MINSAP. Ministerio de Salud Pública. Calle 23 No. 201. El Vedado 10400, Plaza. La Habana, Cuba. 